\title{
STRUCTURAL MODEL OF THE ELECTRIC DRIVE sciendo WITH DOUBLE-FED ASYNCHRONOUS MACHINE AND DIRECT TORQUE CONTROL
}

doi:10.2478/mape-2018-0006

Date of submission of the article to the Editor: 04/2018 Date of acceptance of the article by the Editor: 07/2018

\author{
MAPE 2018, volume 1, issue 1, pp. 41-45
}

Prof. Dr Eng. Sergey German-Galkin

ITMO University Saint-Petersburg, Russia

\author{
Dr Eng. Maciej Kozak \\ Maritime University of Szczecin, Poland
}

\begin{abstract}
At present, the development of modern complex objects management systems, including electric motors, must include the step of modelling studies, which allows you to obtain basic characteristics, slightly different from the real characteristics of the object. The development of an adequate model, which can simulate the system under investigation, eliminates the stage of conceptual design and significantly reduce the engineering design stage, and therefore saves time and money.
\end{abstract}

Keywords: control flux and torque, double-fed asynchronous machine, package Matlab - Simulink

\section{INTRODUCTION}

The idea of moving the control flux and torque of the asynchronous machine, which received recent name of direct torque control DTC, was first proposed in (Onishchenko and Elbow, 1979). Later in 1984, such control method was described under the name of "self-direct" (DSC - direct self-control) (Depenbrock, 1984). Sometime later, the Japanese researchers I. Takahashi and T. Noguchi developed the principle called the "direct control of flux" (DFLC direct flux linkage control) (Takahashi and Noguchi, 1986). In the presented method structure model flux estimation, allows the control process to stabilize of magnetic air-gap flux. The control method that combines DFLC management and machine flux calculated from voltage model (Takahashi and. Ohmori, 1989) with use of DTC abbreviation was described for the first time. In can be concluded that DTC has been developed to regulate flux and torque in the direct way while currents and voltage are regulated indirectly (S. Arnalte et al. 2002). Because of its benefits DTC method can be successfully applied to control of large wind double-fed generators on machine side inverter.

At present, the development of modern complex objects management systems, including electric motors, must include the step of modelling studies, which allows to obtain basic characteristics, slightly different from the real characteristics of the object. The development of an adequate model, which can simulate the investigated system, eliminates the stage of conceptual design and significantly reduce the engineering design stage, and therefore saves time and money. One of the most convenient and proven software tools to create models of arbitrarily complex mechatronic systems is considered a package of Matlab/Simulink. This package has a fairly simple and easy to use interface, includes a large number of libraries of electrical elements, mathematical functions and other tools for the task. Typically, two types of models (German-Galkin and Lyapin, 2012) developed a model for the study of the electrical engineers.

The structural model, which is based on a system of differential equations describing the electromagnetic processes in the drive, commonly used to evaluate the dynamic performance of the drive (Gupta et al., 2013). Virtual model, consisting of the same elements as the real 
system that simulates the operation of the drive, is used to study both dynamic and static characteristics and a preview of stage model-based design. The purpose of this article is to develop a structural model of the asynchronous electric machine with dual power supply and direct torque control.

\section{MATHEMATICAL BACKGROUND}

At the heart of direct torque control method there is the equation for the electromagnetic torque in terms of the magnitude of the rotor flux and the stator and it is given by:

$$
T_{e}=\frac{3}{2} p \frac{k_{1}}{\sigma L_{2}}\left|\psi_{1}\right|\left|\psi_{2}\right| \sin \theta
$$

Dual-voltage stator windings are connected directly to the network thus stator supply voltage during operation is consistent. Therefore, the stator flux linkage value of the transition process, caused by voltage applied to the stator windings will be constant. Constant modulus of the rotor flux and the change of the angle between the rotor and stator flux is ensured by the the regulators action at the output of the inverter resulting in required vector of the rotor voltage creation. Selecting the switching transistors on the inverter generates the required voltage according to the rotor position is carried out with the optimum switching table vector choice (Sokolovsky, 2006) [3]. Vector choice enables not only proper control of bridge transistors in the manner of DTC but also minimizes the loses and utilizes all available direct current intermediate circuitry voltage. What is very important to presented control method the base vector is oriented so that implies $\psi_{1 \mathrm{y}}=0, \psi_{1 \mathrm{x}}=\bar{\psi}_{1}=$ const

The expression for the electromagnetic torque rewritten through vector projections of linkage stator and rotor flux, taking into account the selected orientation, can be expressed as follows:

$$
\begin{aligned}
& T_{e}=-\frac{3}{2} p \frac{k_{1}}{\sigma L_{2}} \psi_{1 x} \psi_{2 y} \\
& \bar{u}_{1}=R_{1} \bar{i}_{1}+\frac{d \bar{\psi}_{1}}{d t}+j \omega_{1} \bar{\psi}_{1} \\
& \bar{u}_{2}=R_{2} \bar{i}_{2}+\frac{d \bar{\psi}_{2}}{d t}+j s \omega_{1} \bar{\psi}_{2} \\
& \bar{\psi}_{1}=L_{1} \bar{i}_{1}+L_{m} \bar{i}_{2} \\
& \bar{\psi}_{2}=L_{2} \bar{i}_{2}+L_{m} \bar{i}_{1}
\end{aligned}
$$

From the equations system (3) the expressions can be found for the projections of the rotor flux linkage and stator as the set of differential equations (4). In the first and second equation there are stator projected linkage fluxes calculated while in the third and the fourth rotor fluxes equations can be found. Additionally, there is fifth equation describing mechanical system. In many technical applications the latter is considered as "slow" in comparison to electrical phenomena and are treated as almost constant in calculation time with regard to sensorless operation of the drive.

In the equations (2) and (4) indicate: $p$ - the number of pole pairs, $s=\frac{\omega_{1}-p \omega_{m}}{\omega_{1}}-$ motor slip.

The following analysis of the electric drive is made for machine characterized by power of 160 $\mathrm{kW}$ and $400 \mathrm{~V}, 50 \mathrm{~Hz}, 1487 \mathrm{RPM}$ with the following set of parameters:

$$
\begin{aligned}
& \omega_{1}=3141 / \mathrm{s} ; \quad p=2 ; R_{1}=0.0138 \Omega ; R_{2}=0.00773 \Omega ; \quad L_{m}=0.0077 \mathrm{H} ; L_{1}=L_{2}=0.00782 \mathrm{H} ; \\
& J=0.29 \mathrm{~kg} \cdot \mathrm{m}^{2}, \mathrm{~T}_{1}=0.567 \mathrm{~s} ., \mathrm{T}_{2}=1.012 \mathrm{~s} ., \mathrm{k}_{1}=\mathrm{k}_{2}=0.985, \sigma=0.03 .
\end{aligned}
$$




$$
\left\{\begin{array}{l}
\frac{d \psi_{1 x}}{d t}=u_{1 x}-\frac{\psi_{1 x}}{T_{1} \sigma}+\frac{k_{2} \psi_{2 x}}{T_{1} \sigma}+\omega_{1} \psi_{1 y} \\
\frac{d \psi_{1 y}}{d t}=u_{1 y}-\frac{\psi_{1 y}}{T_{1} \sigma}+\frac{k_{2} \psi_{2 y}}{T_{1} \sigma}-\omega_{1} \psi_{1 x} \\
\frac{d \psi_{2 x}}{d t}=u_{2 x}-\frac{\psi_{2 x}}{T_{2} \sigma}+\frac{k_{2}}{T_{2} \sigma} \psi_{1 x}+s \omega_{1} \psi_{2 y} \\
\frac{d \psi_{2 y}}{d t}=u_{2 y}-\frac{\psi_{2 y}}{T_{2} \sigma}+\frac{k_{2} \psi_{1 y}}{T_{2} \sigma}-s \omega_{1} \psi_{2 x} \\
J \frac{d \omega_{m}}{d t}=T_{e}-T_{o b c} .
\end{array}\right.
$$

The equations system (4) and the equation describing the torque (2) both are the basis for the development of a structural model of the electric machine with dual power supply and direct torque control. Based on the developed equations there should be two separate channels in the model. The first channel is carried out by forming the rotor voltage rotary axis " $x$ " in accordance with the third equation of the system (4). In the second channel is carried out by forming the rotating rotor voltage axis " $y$ " in the system according to a fourth equation (4). The first channel is performed the calculation of the rotor flux and the projection maintaining it equal to zero. In this channel a difference signal between the desired rotor flux $\psi_{2}=0$ and its actual value is supplied to the on-off control relay. In the second channel calculation is performed with projection of the rotor flux. In this channel a difference signal between the set point and actual value is supplied to the three-position relay control.

\section{STRUCTURAL MODEL AND SIMULATION RESULTS}

On the basis of equations $(3,4)$ a structural model shown in Figure 1 based on the model of the electric drive dual-voltage and direct torque control was developed. The first two equations of the system are implemented in the Subsystem block (4) describing the electromagnetic processes in the stator of the machine. Data calculated in machine equations system are feeding mechanical part of model which contains startup and load apply procedures in $0.1 \mathrm{~s}$ and $0.3 \mathrm{~s}$. respectively.
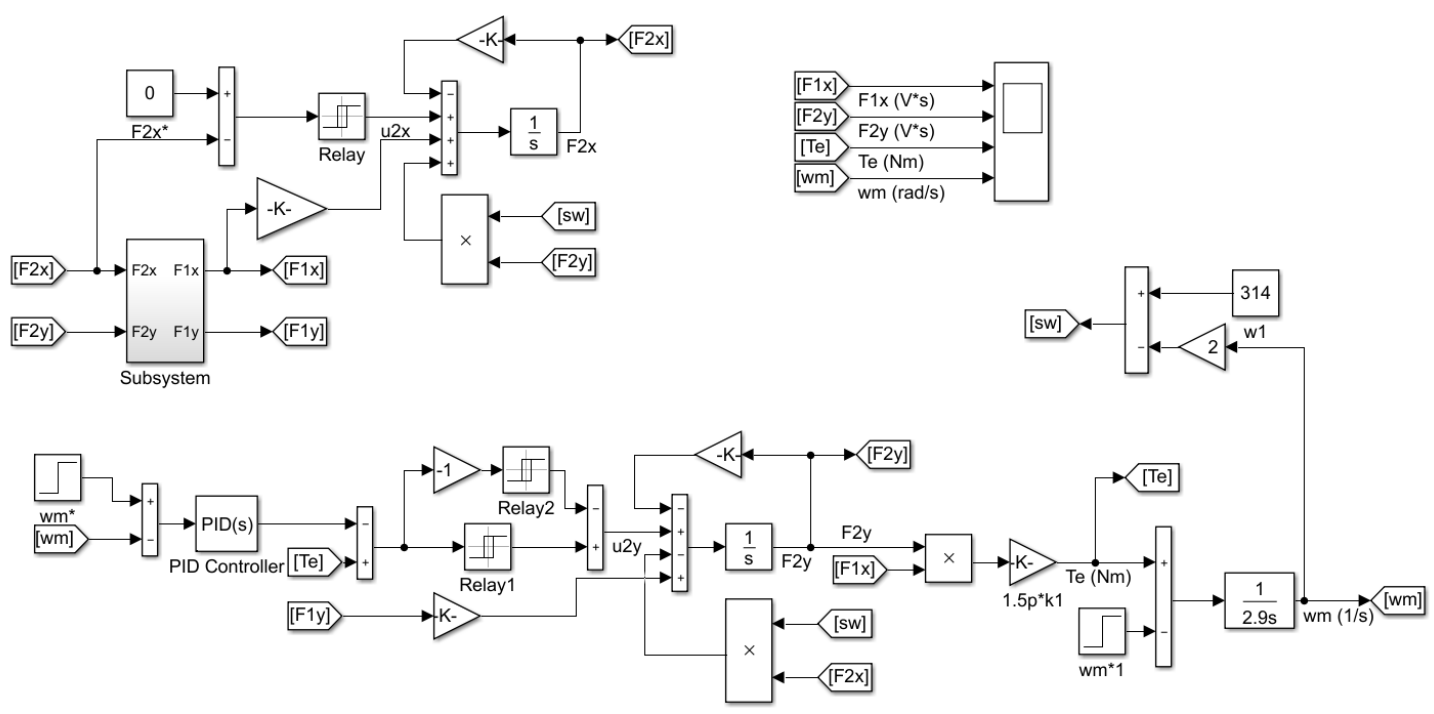

Fig. 1. The structural model of the electric drive with DFAM and direct torque control 
Transients flux linkage, torque and speed in the drive are shown in Fig. 2. When powering on the system transient stator flux current, which is determined only by the parameters of the machine itself, has an oscillatory character and ends quickly. The component of the rotor flux linkage, which determines the time and the moment of change abruptly at a feed rate signal to the actuator input. In this process of transition speed has an aperiodic character. When a torque load is applied, the transients on the rotor flux current, torque and speed have also aperiodic character.

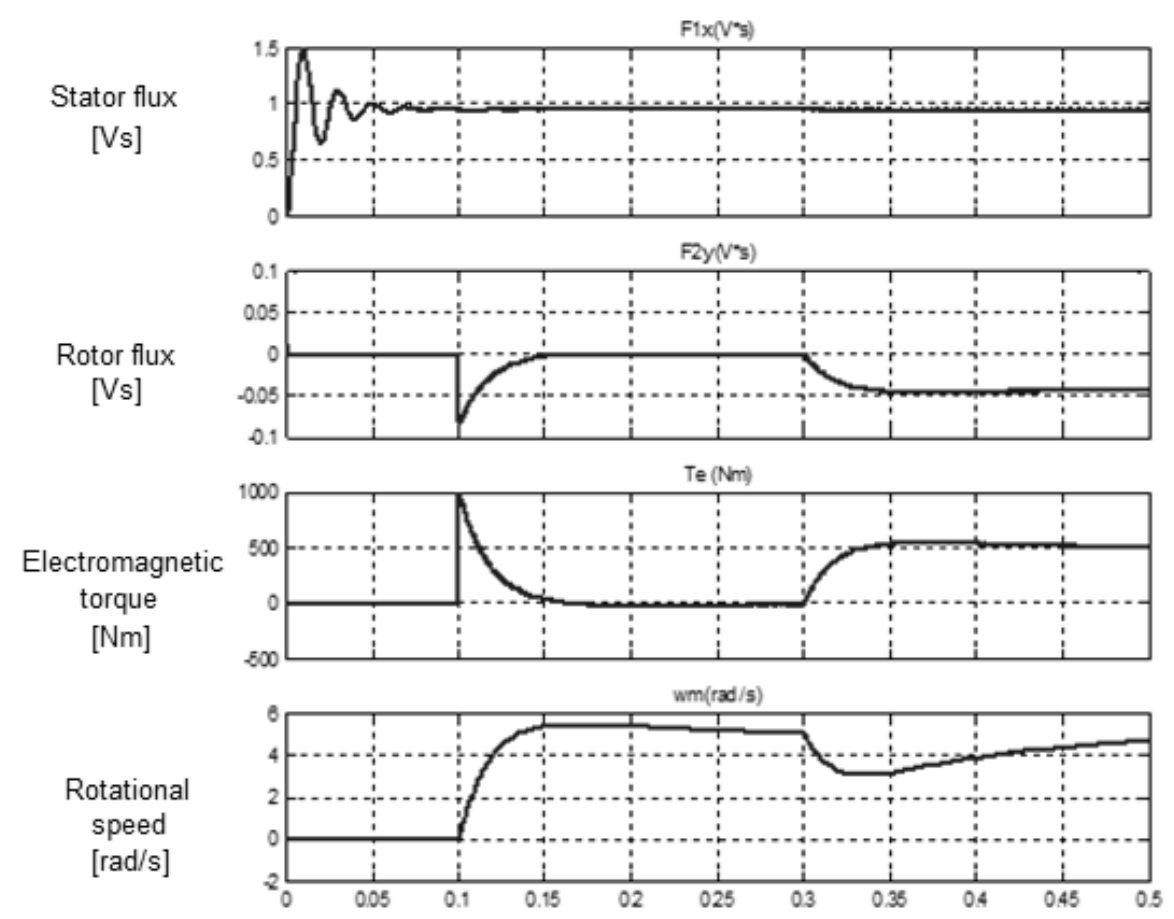

Fig. 2. Transients flux linkage, torque and speed of the drive while speed and load changes

The mathematical model representing the double fed induction machine consists of two parts and its Simulink model representation is shown in Fig.3. In the first one the stator linkage flux (denoted as F1x) is calculated on the basis of voltage input U1x and rotor flux F2x. In the second part of model stator flux F1y in the " $y$ " axis is calculated. Using constant values of fluxes gives convenient way of controlling values with PID controllers. In the real world application calculating of constant values of current, voltages and estimated fluxes is performed with use Park and Clarke transforms.

Use of PID controllers needs adjusting coefficients to obtain stable operation of presented system in wide range of rotational speeds and loads applied to machine shaft. Presented model was tested for stability and proved good dynamic behavior and stable operation in wide range of rotational speed and torque applied. 

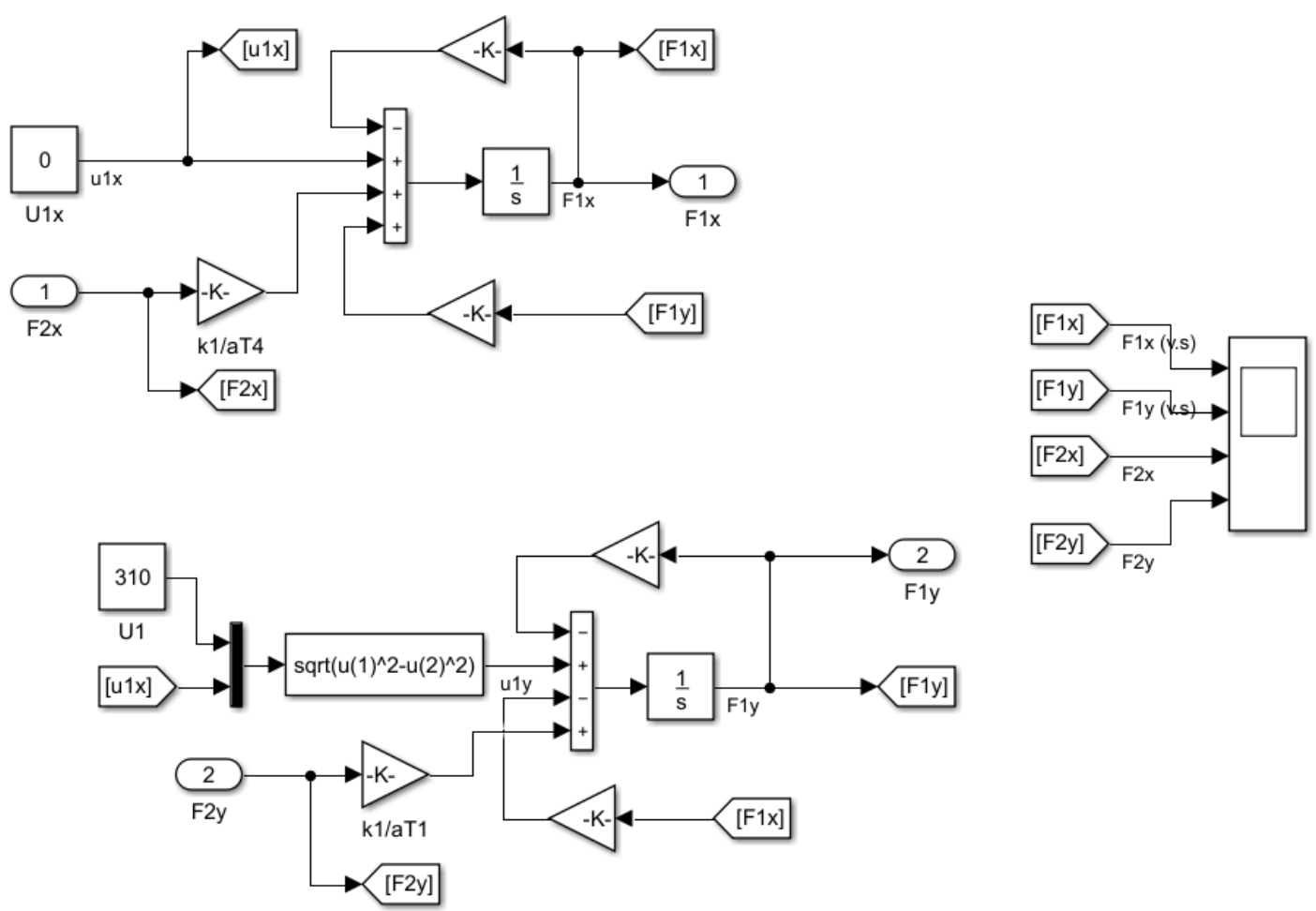

Fig. 3. Subsystem representing reduced mathematical model of double fed asynchronous machine

\section{CONCLUSION}

The DTC method of induction motor control is widely used with squirrel-cage machines because of it's inherent independence on machine changing parameters (rotor resistance etc.). Presented, simplified model of double-fed machine doesn't include end-user application aspects like measurement noises and computational delays but shows good dynamic behavior in wide range of speeds and varying shaft loads. Transition to model utilizing real machine needs a lot work on controllers' coefficients and startup and shut down procedures but presented control method definitely can be applied especially when all machine circuitry is easy available including rotor windings. This property gives possibility to very precise control of torque of double-fed motor working with varying rotational speed.

\section{REFERENCES}

Arnalte, S., Burgos, J.C. and Rodríguez-Amenedo, J.L. (2002). Direct Torque Control of a Doubly-Fed Induction Generator for Variable Speed Wind Turbines. Electric Power Components and Systems, 30:199-216, 2002, Taylor \& Francis.

Depenbrock, M. (1988). Direct Self-Control (DSC) of Inverter-Fed Induction Machine. IEEE Transaction On Power Electronics, 1988. Vol.3, 4.

German Galkin, S. and Lyapin, A. (2012). Analysis and modeling study of asynchronous electric drive with sliding flux control. Mechatronics, Automation, Control, N.4, 2012.

Gupta, A., Singh S.N. and Khatod, D.K. (2013). Modeling and Simulation of Doubly Fed Induction Generator Coupled With Wind Turbine An Overview. Journal of Engineering, Computers \& Applied Sciences (JEC\&AS) ISSN No:2319 5606 Volume 2 , No.8, August 2013.

Onishchenko, G.B. and Lokteva, I.I. (1979). Induction valve cascades with double-fed asynchronous machine. Moscow: Energy.

Sokolovski, G.G. (2006). Electric drive with frequency regulation. Moscow: Academia publishing center, 2006.

Takahashi, I. and Noguchi, T. (1986). A New Quick-Response and High-Efficiency Control Strategy of an Induction Motor. IEEE Transaction On Industry Application. 1986. Vol. 22, 5.

Takahashi, I. and Ohmori, Y. (1989). High-Performance Direct Torque Control of an Induction Motor. IEEE transactions on industry applications, vol. 25, no. 2, march/april 1989. 